\title{
Grammatical mistakes of Albanian students in learning English as a foreign language
}

\author{
Lindita Kaçani \\ University of Korca \\ Ikacani@yahoo.com
}

DOI:10.5901/mjss.2014.v5n19p323

\begin{abstract}
Mistakes are an unavoidable part of the foreign language learning and teaching. This paper concentrates on the common grammatical mistakes made by Albanian students during the EFL learning process and their sources with the purpose of considering them in teaching the English grammar effectively. Being aware of such mistakes in teaching and learning English grammar for communicative purpose may help the teacher in choosing the right teaching option that would pose fewer difficulties and problems to their learners and therefore, enhance students' learning of English grammar. The background of this study consists in some important clarifications regarding the terminology (errors, mistakes), typology and causes of mistakes. The terms error and mistake in this study are used synonymously, referring to the production of inaccurate forms in learners' language output. It is noted that many of the mistakes are caused by the influence the learners' native language. Some of the most common mistakes of Albanian learners are: verb agreement, tense use, question and negative forms, verb patterns, elliptic structures, articles and prepositions. Many of them have been identified by other foreign researchers. The errors have been gathered form a corpus of written texts produced by 40 students of the first course studying English as a foreign language at the English Department, Faculty of Education, "Fan S. Noli" University in Korca, in the academic year 2013-2014. The model of correct usage employed in this paper is standard British English. The paper concludes with a discussion of what appears to be the most important issues arising from the survey.
\end{abstract}

Key words: Grammatical Mistake, Error, Cause, Type, Native Language Interference.

\section{Introduction}

This paper stems from Kennedy's statement: "...learners typically make errors or have learning difficulties that are characteristic of their particular language background" (Kennedy, 2003, p. 4). Naturally, the following questions arose: What learning difficulties do Albanian learners of English (as a foreign language) have with regard to grammar? Are there any typical errors, besides those that are found in common among learners from many different language backgrounds?

Based on my fifteen-year experience as a teacher of English (as a foreign language), many linguistic aspects (as phonetic, lexical and grammatical) are often found difficult to be internalized though they are often reviewed and practiced in English classes, such as verb use (including tense, aspect, non -finite verb forms, phrasal verbs), and prepositions; these linguistic aspects are identified as common mistakes of learners from other different language backgrounds. As Kennedy stated "experienced teachers of English have found that learners from many different language backgrounds have certain problems in common". According to Kennedy, the most difficult linguistic aspects to learn how to use are: articles and other determiners, prepositions, verb use (including tenses, modal verbs, participles, infinitives and phrasal verbs), subordinate clauses, verb complements and ellipsis.

This study attempts to draw on the common grammatical mistakes or errors made by learners of English as a foreign language at 'Fan Noli' University, Faculty of Philology and Education, English Department. The results of this study may have a positive advantage particularly for foreign language teachers in improving grammar teaching in classroom-based settings and generally for other researchers in further studies on the matter.

\section{Literature review}

\section{The definition of errors and mistakes}

The term "error" has been differently defined over the years. As Pawlak (2012) noted, specialists have not reached an agreement on a satisfactory definition of this term, adopted as a point of reference in the analyses of learners' inaccurate 
production (p. 3). Let us see some of the definitions. Lennon (1991) defined an error with a reference to the native speaker norm by describing it as "[a] linguistic form or a combination of forms, which, in the same context and under similar conditions of production, would, in all likelihood, not be produced by the speakers' native speaker counterparts" (p. 182). But this definition is not seen satisfactory since, as Pawlak (2012) mentioned, there are different varieties of the target language (such as British and American English) and "... the definition of an error should be modified to some extent so that it will be more reflective of classroom reality" (p. 4).

Referring to Ridha (2012), Norrish (1987) and Cunningworth (1987) also considered target language norms in defining errors respectively as "a systematic deviation, when learner has not learnt something and consistently gets its wrong" ( $p$. 7) and "systematic deviations from the norms of the language being learned" (p. 87), but differently from Lennon, they considered errors as repeated deviations.

Other researchers, when talking about errors, draw distinction between errors and mistakes. According to Corder, "a mistake is a problem not of knowing but of application" (Tafani, 2009). Corder has identified errors as "deviant forms which cannot be self-corrected because the learner is not familiar with the rule", while mistakes as "performance errors that can be repaired by learners themselves when incorrect forms are pointed out to them by the teacher or a more proficient language user" (cited in Pawlak 2012, p.122).

James (1998:83) also tried to differentiate between them. He defined errors as "cannot be self corrected" whereas mistakes as "can be self corrected if the deviation is pointed out to the speaker".

Similarly, Richards and Schmidt (2002), in Dictionary of Language Teaching and Applied Linguistics, distinguished errors from mistakes with a reference to linguistic knowledge and performance by defining an error as "the use of linguistic item in a way that a fluent or native speaker of the language regards it as showing faulty or incomplete learning", whereas "a learner makes mistakes when writing or speaking because of lack of attention, fatigue, carelessness, or some other aspects of performance. Thus, mistakes can be self-corrected when attention is called" (p. 184).

Moreover, Ellis (2008) differentiated between errors and mistakes: the former are thought to be characteristic of non-native speakers and result from the lack of knowledge, the latter concern performance and be "regular features of native-speaker speech, reflecting processing failures that arise as a result of competing plans, memory limitations and lack of automaticity" (p. 48).

Differently from the above researchers, Pawlak (2012) treated the terms error and mistake as synonymous in his study, referring to the production of inaccurate forms in learners' oral and written output. For Pawlak, such a distinction is of minor importance in front of other issues related to errors and mistakes such as the decision to or not to correct mistakes, the moment and the proper strategies needed to treat an incorrect linguistic form. Thus, supporting Pawlak, in this study, the terms error and mistake are going to be used synonymously referring to the production of inaccurate forms in learners' oral and written output.

\section{Sources of Errors}

Error analysis (EA) is an approach to understanding second language acquisition which consists of compiling a corpus of L2 learner deviations from the target second language norms the 'errors' learners make. It has contributed to classifying these errors by type and hypothesizing possible sources for the errors (Johnson \& Johnson, 1999).

Categorization of errors relating to their source, like error definition, has been controversial. At the beginning of EA, it was believed that all the errors can be attributed to interference. But further research has identified other sources of incorrect linguistic production.

Richards (1971) distinguished three causes of psycholinguistic errors: interference errors, attributed to the influence of one's native language, intra-lingual errors, resulting from ignorance or inaccurate application of rules, and developmental errors, attributable to the inconsistencies of the developing system.

Ellis (2008) related the types of errors to learners' level and type of the activities:

beginners and elementary learners commit more transfer errors and fewer intra-lingual ones; advanced learners produce more intra-lingual and fewer transfer errors;

translation exercises tend to generate more transfer errors than other types of exercise (p. 55).

Brown (2000) identified: 
inter-lingual (across two or more languages) errors resulting from transfer from the native language to other languages. Transfer is categorized of two kinds: positive (the case when the transfer may prove to be justified because the structure of the two languages is similar) and negative (when it may prove unjustified because the structure of the two languages are different);

intra-lingual (developmental) (within one language) errors resulting from faulty or partial learning of the target language rather than language transfer. Such errors include: overgeneralization (resulting from extension of target language rules to inappropriate contexts), simplification (resulting from producing simpler linguistic rules than those found in target language), communication-based (resulting from strategies of communication), induced errors (resulting from the way in which a linguistic item has been practiced or presented), avoidance (resulting from failure to use certain target language structures because of being thought to be too difficult) and errors of overproduction (resulting from too frequently use of structures) (Johnson \& Johnson, 1999; Richards \& Schmidt, 2002, p. 185);

context of learning including the teacher (because of his misleading explanation/ incorrect information), the textbook (faulty presentation).

Broughton and his colleagues (1980), also, in addition to errors from learning process and mother tongue interference, listed poor teaching materials, inappropriate use of materials and faulty teaching as the main reasons for errors (p. 137).

However, as the aim of teaching and learning a foreign language is communication, it is important to view errors and mistakes as "evidence of the learner's willingness to communicate, despite risks" (Council of Europe, 2001, p. 155). As Edge stated "... people may say things that they know are not correct, because this is still their best chance of getting their message across". Such learners though have not internalized certain structures yet, continue their communication in English.

\section{Types of errors}

Errors have been classified in different ways. Corder (1971, cited in Brown, 2000) classified errors in terms of the differences between the learners' utterance and the reconstructed version in the target language. Referring to his model, Brown made a distinction between overt and covert errors: "Overtly erroneous utterances are unquestionably ungrammatical at the sentence level. Covertly erroneous utterances are grammatically well-formed at the sentence level but are not interpretable within the context of communication" (p. 220).

Brown has also noted other different categories for describing errors, as following:

Very generalized categories: errors of addition (I do can sing), omission (I am student), substitution (do a promise) and ordering (To whom does this belong?);

Levels of the language: phonology, orthography, lexicon, grammar and discourse errors. Richards and Schmidt (2002) identified discourse errors as errors resulting from misunderstanding of a speaker's intention or meaning (interpretive error) and those resulting from production of the wrong communicative effect (pragmatic error), (p. 184).

Degree of violation of the sentence: global and local errors (referring to Burt and Kiparsky, 1972); the first prevent the receiver of the language form comprehending the message as they affect overall sentence organization (English language use many people); the latter refers to errors that do not prevent the receiver of the message to understand it as they affect only one element in a sentence (He speak English).

Richards (1971) compiled a corpus of English errors produced by speakers from eleven different language backgrounds and classified them by their linguistic type, as errors:

- $\quad$ in the production of the verb group (He was died last year);

- $\quad$ in the distribution of verb groups (I am having my hair cut on Thursdays);

- $\quad$ in the use of prepositions (entered in the room);

- $\quad$ in the use of articles (She goes to bazaar every day);

- $\quad$ in the use of questions (Why this man is cold?);

- $\quad$ of a dustbin category of miscellaneous errors (I am very lazy to stay at home; this is not fit to drink it) (Johnson \& Johnson, 1999, p.111). 
Other researchers have identified the items that learners of English find difficult. Referring to Kennedy (2003, p. 3-4), Close (1962) listed the following as particularly difficult aspects of grammar for learners of English: when to use or omit the or a; whether to say I write or I am writing, have written or wrote, wrote or had written; how to use have been writing and had been writing; how to use could, would, should, might, must; whether to use the infinitive or the form of the verb ending in ing; which preposition to use after a verb or before a noun; whether to use some or any, each or every; where to put adverbs in a sentence; whether to use say or tell, do or make.

Barry Taylor (1975, cited in Brown 225-6) identified nine types of different of intra-lingual errors commonly encountered in English learners from different native language backgrounds: past tense form of verb following a modal, present tense $-\mathrm{s}$ on a verb following a modal, -ing on a verb following a modal, are following will, past tense form of verb following do, present tense -s on a verb following do, -ing on a verb following do, past tense form of a verb following be, present tense - $s$ on a verb following be.

Richards (1971) identified the typical intra-lingual errors in the use of articles: omission of 'the', 'the' used instead of zero article, 'a' used instead of 'the', 'a' used instead of zero article, omission of 'a'.

Ridha (2012) identified the following grammatical aspects that Arabic learners of English find difficult in writing: verb use (tense, aspect, voice, articles, singular/plural nouns, pronouns and prepositions.

As it is seen, learners from many different language backgrounds have certain problems in common, which are mainly related to the grammatical aspect.

\section{Method of the Study}

The aim of this study is to examine the errors of Albanian university students of EFL and to analyze the sources of these errors.

The data used for this research has derived from the written production of 40 students of the first course studying English as a foreign language at the English Department, Faculty of Education, "Fan S. Noli" University in Korca, in the academic year 2013-2014. These students studied grammar in morphology course and syntax one; each of them consisted of 75 classes, mainly concerned with the study of basic concepts in grammar and the standard grammatical description of the language including the structure of words, phrases, clauses and sentences. The data came from six pieces of writing that the students were requested to write on at their time during one month period, at the end of the grammar course, for evaluation purpose. Their topics are appended at the end of the paper.

The model of correct usage employed in this paper is standard British English.

\section{Findings and discussion}

Albanian students did different grammatical errors. Most of them are errors identified by researchers of other language backgrounds (as discussed above). The grammatical errors (analyzed at both word and sentence levels) and their reasons are described in the following lines.

Starting with the verb use, it is noticeable the use of incorrect negative or interrogative sentences, especially in the simple present and simple past tenses because there is no equivalent of auxiliaries (do, does and did) in Albanian (example: "I not stay / stayed late' instead of 'I don't/didn't stay late; 'How I look?' instead of 'How do I look'?)

Furthermore, omission of the verb 'to be' in the continuous form of a verb (present continuous, past continuous, present perfect continuous, past perfect continuous or future continuous) is sometimes identified (example: 'I talking to him' instead of 'I am / was talking to him'). It is 'sometimes' because students have mainly made use of common (simple) aspect than continuous one; the reason is that simple aspect in Albanian covers the meaning of English simple and continuous aspect. These errors are of negative transfer because there is no equivalent form between English continuous and perfect aspect forms and Albanian ones.

Different tense forms of the verb are misused in different kinds of sentences especially in indicative and conditional ones. For example: a) 'When I will see him ...', b) 'If I will see him...', instead of 'When I see him....', 'If I see him...'. In these examples, influenced by Albanian, learners use the modal auxiliary verb 'will' with a reference to the particle 'të' or 'do të' in Albanian subjunctive or conditional mood $(\mathrm{a})^{‘}$.... të shikoj atë ...', b) '... do të takoj ...'.

Other forms of the verb are also confusing to the learners: 
past tense and participle forms of irregular verbs. For example: 'teached' instead of 'taught', 'have drank' instead of 'have drunk' - this is the case of overgeneralization (extension of target language rules to inappropriate contexts);

use of to-infinitive or -ing forms of the verb (to express purpose: 'I have come here for saying' instead of 'I have come here to say...'; after certain verbs: 'enjoy to read' instead of 'enjoy reading'). Based on literal translation, the students confuse the use of to-infinitive and -ing form of the English verbs.

Another common error is the incorrect use of modal verbs in indicative and conditional sentences. The number of modal verbs in Albanian is smaller than in English; generally, English modal verbs (such as can, could, may, might, must have to, should) are translated to two Albanian modals (duhet and mund). For this reason the learners find the use of modal verbs with reference to different meanings difficult. For example: 'That mustn't be Tom' instead of 'That can't be Tom'. This is a case of source of overproduction; generally students use 'must' too frequently to refer to different meanings.

Incorrect plural form of uncountable nouns and irregular countable nouns is another error example because of overgeneralization (example: 'some informations / advices / childrens' instead of some information / advice / children). Based on literal translation, Albanian students use regular plural form for uncountable English nouns as these nouns are countable in Albanian. The same explanation rests for the following error.

Disagreement of subject and verb in a sentence (example: 'The news are fantastic' instead of 'The news is fantastic').

Using the appropriate preposition is one of the most difficult tasks of EFL learners; this is because in English there are various prepositions which have the same function and use of certain Albanian prepositions. For example: in English: go to school / be at a party; in Albanian: shkoj në shkollë / jam në një mbrëmje; as it is seen from these two examples, two different prepositions are used in the English phrases, while the same preposition 'në' is used in the equivalent Albanian phrases. Thus, Albanian learners, based on literal translation, often use an incorrect preposition. Based on my teaching experience, this is also true when referring to their oral production:

in, at, on (example: 'Write something in the board instead of 'Write something on the board)

after certain verbs (example: 'Concentrate in it' instead of 'Concentrate on it')

after certain nouns (example: 'a solution of the problem' instead of 'a solution to the problem')

after certain adjectives (example: 'Everybody was surprised with the news' instead of 'Everybody was surprised at / by the news')

Articles are also misused by students: use of 'a / an' with uncountable nouns, omission of 'a/an/the', use of the instead of zero article (example: 'had a good weather', 'he is student', 'the Albania', ' a program on TV about the dolphins' instead of 'had good weather', 'he is a student', 'Albania', 'a program on TV about dolphins'). They are confusing because Albanian language, unlike English, does not make use of any preceding morphemes to make a noun definite; the use of numeral one ("një") that refers to the indefinite article a (një student - a student) is optional when using an indefinite noun. The definite Albanian morphemes are attached to the nouns at the end.

The misusing of many pronouns can be attributed to the negative transfer of native language. In Albanian, the use of indefinite pronouns does not depend on the type of the noun it combines and on the type of sentence where it is used. For example: 'many money', ' much friends', 'He has much money' instead of 'a lot of money', 'many friends', 'He hasn't much money'. Moreover, pronouns are problematic because there are no exact equivalent counterparts in both languages (English and Albanian), for example, the pronoun it. EFL students omit it in sentences where it is used as an impersonal pronoun (example: 'is raining' instead of 'it's raining' because no subject is used in Albanian impersonal sentences. Also the students use incorrectly 'he 'or 'she' for inanimate objects or concepts.

Faulty word order is a common syntactic error that the learners commit as a result of native language transfer. They have often come up with constructions that are applicable in Albanian. For example: position of adjectives in a phrase or sentence (example: 'main problem is economic' 'She has long beautiful hair', 'I would like a big enough house' instead of 'main problem is economic one', 'She has beautiful long hair', 'I would like a house big enough'); position of adverbs in a sentence (example: 'I like very much football', 'my family still is abroad', ' go by train to the airport' instead of 'I like football very much', ' my family is still abroad', go to the airport by train').

The use of incorrect comparative and superlative forms of the adjectives and adverbs is another common mistake of these learners. For example: 'this is more easier / more easy than.../ the most funniest', 'drive more faster' instead of 'this is easier than... / the funniest', 'drive faster'. Influenced by Albanian language (comparative - më i lehtë / më lehtë, superlative 
- më i lehti), students use the adverb 'more / most' before one- and two-syllable adjectives, besides the use of the comparative or superlative morpheme -er or -est.

In the same vein, the learners use comparative structures as 'I prefer tea than coffee' instead of 'I prefer tea to coffee'.

The form of adverbs is also confused with those of adjectives. As in Albanian the same form can be used as an adjective (është i keq - is bad) and as an adverb (e traiton keq - treats him badly), the learners use an adjective form 'She treated him so bad' for an adverb one 'She treated him so badly'.

Incorrect use of elliptic structures: 'A: Did you visit your friend yesterday? B: Yes, I visited' instead of 'Yes, I did'; that is because in such Albanian sentences it is used the verb itself, not the auxiliary verb.

Based on these findings, it should be noted that most of the Albanian learners' mistakes are caused by the influence of their native language, whereas some of them are caused by overgeneralization, simplification, avoidance and overproduction.

\section{Conclusions}

It is totally agreed among researchers of foreign language acquisition that mistakes or errors are an unavoidable part of the foreign language learning and teaching. But it is different when talking about their definitions and categorization relating to their source and types. Error analysis has contributed to the change of the way errors are perceived and treated in foreign language acquisition.

Differentiating between learners' errors (identified as problems of knowing) from mistakes (as problems of performance) is not an easy task for FL teachers especially at a teaching and learning context where: the learners have participated in the grammar course; and there is a large and mix-ability class. For this reason, in this study, the terms error and mistake were used synonymously, referring to the production of inaccurate forms in learners' oral and written output.

It is also difficult to identify all the sources of infelicitous language use (as identified by various researchers of foreign language acquisition), just through an article; however, the findings showed that most of the Albanian learners' mistakes are caused by the influence of their native language, whereas some of them are caused by overgeneralization, simplification, avoidance and overproduction. Many of the identified mistakes are common to other foreign learners of different language backgrounds: articles, pronouns, verb use (including tenses, aspect, modal verbs, participles, infinitives, phrasal verbs), negative and interrogative form of sentences and prepositions. Other mistakes are due to the characteristics of their native language. When a student does not know how to express what he wants to say, he often makes a guess on the basis of his knowledge of his native language and foreign language. The findings showed that Albanian learners have learning difficulty in other certain grammatical structures: incorrect plural form of uncountable nouns and irregular countable nouns, faulty word order (especially of adjectives and adverbs), incorrect comparative and superlative forms of the adjectives and adverbs, the form of adverbs confused with those of adjectives.

Though the above grammatical aspects had been in the focus of instruction during the grammar course, further exposure of grammatical knowledge and target language input and opportunities for language output are needed for the learners as to help them enhance the target grammar and language acquisition. For this purpose teachers need to select the appropriate instructional strategy in order to address the needs of their learners.

\section{References}

Broughton, G., Brumfit, C., Flavell, R., Hill, P. \& Pincas, A. (1980). Teaching English as a Foreign Language. Second edition. Routledge, London \& New York.

Brown, H. D. (2000). Principals of language learning and teaching. (4 Ed.). Longman: Addison Wesley Longman.

Corder, P. (1999). "The Significance of Learner's Errors"

Council of Europe. (2001). The Common European Framework of reference for languages: learning teaching and assessment, Cambridge University Press.

Edge, J. (1989). Errors and mistakes. Longman keys to language teaching. Longman Group UK Limited.

Ellis, R. (2008). The study of second language acquisition. (2 Ed). Oxford University Press. 
Johnson, K. \& Johnson, H. (1999). Encyclopedic Dictionary of Applied Linguistics: A Handbook for Language Teaching. Blackwell Publishing Ltd.

Kennedy, G. (2003). Structure and Meaning in English: A Guide for Teachers. Pearson Longman.

Lennon, P. (1991). Error: Some problems of definition, identification and distinction. Applied Linguistics, 12, 180-196.

Pawlak, M. (2012). Error Correction in the Foreign Language Classroom: Reconsidering the Issues. Springer.

Richards, J. C. \& Schmidt, R. (2002). Longman Dictionary of Language Teaching and Applied Linguistics. Pearson Education Limited.

Richards, J. C. (1971). "A non-contrastive approach to error analysis", ELT Journal, 25, 204-219.

Ridha, N. S. (2012). The Effect of EFL Learners' Mother Tongue on their Writings in English: An Error Analysis Study. Journal of the College of Arts. University of Basrah, 60, 22-45.

Tafani, V. (2009). Correcting or not Errors and Mistakes. LCPJ Publishing, 2(2), 49-57.

\section{Appendix}

Topics for six pieces of writing

Write a true story about you choosing one of these topics: you met a famous person; you did something very dangerous; you went to a very strange place.

Think about home, work, family, sport and hobbies. What changes have you made recently? What changes do you want to make?

Describe plans for a trip (the places you visit, how long it goes on, the start and the finish times, etc). Choose between: a boat trip on a river; a walking tour around a city.

Imagine being alone for a hundred days in one of these situations: a) a single-handed yacht race / boat b) on a desert island. Describe how would you feel / think.

What is your opinion about the future of these things: toys and games, cars and transport, multi-media equipment and clothes?

Write an e-mail to your friend telling him what to do or not to do in one of the following situations: a) you are going out for dinner with your new boss b) you are meeting your girlfriend / boyfriend' parents for the first time. Consider: time to arrive, good/bad conversation topics, what to wear, food / drink to have. 